\title{
Comparative autohydrolysis study of two mixtures of forest and marginal land resources for co-production of biofuels and value-added compounds
}

\author{
Rita Pontes a, b, c, Aloia Romaní ${ }^{\text {b, * , Michele Michelin }}{ }^{\mathrm{b}}$, Lucília Domingues ${ }^{\mathrm{b}}$, \\ José Teixeira ${ }^{b}$, João Nunes ${ }^{a}$ \\ a Association BLC3 - Technology and Innovation Campus, 3405-155 Oliveira do Hospital, Portugal \\ ${ }^{\mathrm{b}}$ CEB-Centre of Biological Engineering, University of Minho, Campus Gualtar, 4710-057 Braga, Portugal \\ ${ }^{c}$ CNC-Center for Neuroscience and Cell Biology, University of Coimbra, 3004-504 Coimbra, Portugal
}

\section{A R T I C L E I N F O}

\section{Article history:}

Received 24 September 2017

Received in revised form

11 March 2018

Accepted 15 May 2018

Available online 18 May 2018

\section{Keywords}

Multi-supply lignocellulosic biomass

Autohydrolysis

Enzymatic hydrolysis

Biorefinery

Solid biofuel

\begin{abstract}
A B S T R A C T
This work was focused on evaluating two mixtures of lignocellulosic feedstock, forest and marginal land resources, in order to co-produce solid biofuel, oligosaccharides, and glucose under a biorefinery concept. The selection of renewable bio-mixtures was based on different criteria, namely, territorial distribution, fire risk during summer months and total sugar content. The two mixtures were submitted to autohydrolysis pretreatment under non-isothermal conditions (in the range of $190^{\circ} \mathrm{C}-240^{\circ} \mathrm{C}$ corresponding to severity of 3.71-4.82). Both mixtures were compared in terms of fractionation (cellulose and lignin recoveries and hemicellulose solubilization), analyzed for thermal properties (high heating values) and for enzymatic susceptibility of cellulose. The highest xylan recoveries (62 and 69\%), as xylose and xylooligosaccharides, were achieved for both mixtures in the liquid phase at $206^{\circ} \mathrm{C}$. Autohydrolysis pretreatment increased the high heating values of the two mixtures presenting an alternative use of solid fraction as solid biofuel. Moreover, enzymatic susceptibility of these pretreated mixtures was also improved from 45 to $90 \%$ of glucose yield by increasing pretreatment severity. This comparative study of autohydrolysis showed a suitable process for the valorization of both mixtures within a biorefinery concept.
\end{abstract}

(C) 2018 Elsevier Ltd. All rights reserved.

\section{Introduction}

In Portugal, the territory is divided in wood and uncultivated land (22\%); forest of pure and mixed stands of Pinus pinaster and Eucalyptus globulus (21\%); and farm land (33\%), mainly composed by olive groves, vineyards and orchards, that generate significant amount of lignocellulosic biomass (LCB) [1]. Approximately half of the national territory $(40 \%-50 \%)$ consists of poor soils with no potential for profitable agricultural use. On average, $60 \%-70 \%$ of the total fires take place in forested and uncultivated areas, resulting in a loss of roughly 800 million Euros annually [2]. So far, there is no sustainable alternative for the use of this territory and no viable solution for forest biomass valorization [2]. Social and economic benefits could be achieved from the utilization of these

\footnotetext{
* Corresponding author

E-mail address: aloia@ceb.uminho.pt (A. Romaní).
}

raw materials in order to develop the so-called bioeconomy, which would boost the creation of new rural jobs [3].

Forest and agricultural residues are the most important sources of lignocellulosic biomass [4]. LCB are the most abundant renewable resource in the world, generated at high rate [5] and suitable for production of energy, biofuels, chemicals, paper, pharmaceuticals and biomaterials $[3,6]$. LCB are composed by $50 \%-60 \%$ carbohydrates, namely, cellulose and hemicellulose and $10 \%$ to $30 \%$ of lignin, together with non-structural components (including ashes, extractives, pectin and proteins) in lower proportions [7-9]. Nevertheless, the conversion of LCB into chemicals is one of the main challenges for biomass processing due to their complex threedimensional structure, requiring multidisciplinary approaches to achieve their integrated benefit [5].

The chemical utilization of LCB can be carried out using two different approaches: (i) utilization as a whole (for example combustion, gasification or pyrolysis), or (ii) using methods based on the selective separation of its components (cellulose, 
hemicellulose, lignin) [3]. The latter process can be based on multistep processing, starting with separation of easily recovered fractions (extractives and hemicellulose) from the more resistant ones (cellulose and lignin), which could be further fractioned by means of more aggressive treatments [5]. Hydrothermal pretreatment has been successfully applied to LCB. This eco-friendly process, also known as autohydrolysis, requires no other reagents than water and high temperature, which enables a wide variety of reactions without the need of a catalyst $[10,11]$. Autohydrolysis provides several advantages, such as: i) high hemicellulose recoveries; ii) no catalyst is necessary; iii) no equipment corrosion problems are expected; iv) stages of sludge handling and acid recycling are avoided; v) enzymatic susceptibility of cellulose is improved [9]. The autohydrolysis reaction solubilizes selectively hemicellulose into oligosaccharides and promotes lower liberation of compounds derived from lignin and cellulose, as well as hemicellulose degradation products [12]. The main compounds found in the remaining solid fraction are cellulose and sulfur-free lignin. Cellulose can be subjected to enzymatic hydrolysis to produce glucose, an important input for biofuels [13] [12].

The use of feedstock mixtures rather than a single raw material can minimize the problems related to biomass availability, seasonality, price volatility and storage. In this work, broom (Cytisus sp.), carqueja (Genista tridentate), mimosa (Acacia dealbata), rockrose (Cistus ladanifer), eucalyptus (Eucalyptus globulus) and pine (Pinus pinaster) were identified as the most important sources of forest fire cases in Portugal. Since the security supply for biorefineries and the sustainability of exploration are key factors to ensure the industrialization of these systems, the aim of this study was to evaluate feedstock mixtures fractionation to supply a biorefinery throughout the year to produce bioenergy and valueadded compounds. Two feedstock mixtures were selected and subjected to autohydrolysis treatment in the range of $190^{\circ} \mathrm{C}-240^{\circ} \mathrm{C}$, in order to evaluate and compare the pretreatment effect on fractionation of feedstock mixtures by hemicellulose solubilization. Besides oligosaccharides, two other alternatives were evaluated for valorization of pretreated feedstock mixtures: solid biofuel production and enzymatic saccharification of cellulose into glucose.

\section{Materials and methods}

\subsection{Raw materials and criteria of feedstocks mixture}

Lignocellulosic biomass collecting through the year was divided into four quarters, considering the biomass from 1 st and 4th quarters (winter months) as mixture 1-4 (M1-4) and from 2nd and 3rd quarters (summer months) as mixture 2-3 (M2-3). The M1-4 and M2-3 were set with different lignocellulosic biomasses from forest ecosystems (A) (namely, eucalyptus and pine) and from marginal land (B) (namely, broom, carqueja, mimosa and rockrose). The criteria for the formulation of $(A)$ and $(B)$ were taking into account their proportion of territorial occupation, based on the National Portuguese Forest Inventory [14]. These percentages were considered to establish the proportion of lignocellulosic biomass for M2-3. The collection of biological resources from marginal land (B) during winter months (1st and 4th quarters) provide reduction of fire risks in the summer months (2nd and 3rd quarters) therefore, a preference factor of $2: 1$ of biomass from marginal land (B) to forest ecosystem (A) was considered in order to establish the M1-4 (Table 1). The percentage of eucalyptus and pine present in M1-4 and M2-3 was also based on area in the Portuguese territory for these species [15]. For the percentages of biomass from marginal land, the weight ratio among broom, mimosa, carqueja and rockrose was calculated as a function of total sugars content [1], since there is no information available regarding territorial distribution of biological resources from marginal land.

The mixtures M1-4 and M2-3 were prepared, homogenized and then characterized as described below. The raw materials resulting from forest management practices, namely, broom, carqueja, mimosa, rockrose, eucalyptus and pine, were collected in the Center Region of Portugal, from a location with the same type of soil. The lignocellulosic biomasses included branches and twigs with barks and leaves. The raw materials were air-dried until moisture lower 5\%, milled and sieved between 0.25 and $0.40 \mathrm{~mm}$ using a vibratory sieve shaker (40 and 60 mesh), and stored in dry conditions to avoid the self-biodegradation of the material. After that, the samples were homogenized in a single lot to avoid compositional differences among aliquots and were stored in polypropylene bags at room temperature.

\subsection{Analysis of raw material}

Analytical assays were performed according to the procedures provided by National Renewable Energy Laboratory (NREL), appropriated for bioenergy production [15]: moisture (NREL/TP510-42621), ash content (NREL/TP-510-42622), extractives (NREL/ TP-510-42621) and quantitative acid hydrolysis with $72 \% \mathrm{w} / \mathrm{w}$ sulphuric acid (NREL/TP-510-42618). The hydrolysates from acid hydrolysis were analyzed by high performance liquid chromatography (HPLC) for sugars (glucose, xylose and arabinose) and acetic acid using the column Aminex HPX-87H (conditions: refractive index detector; flow rate of $0.6 \mathrm{~mL} / \mathrm{min}$ at $60^{\circ} \mathrm{C}$; $0.005 \mathrm{M} \mathrm{H}_{2} \mathrm{SO}_{4}$ as mobile phase) and HPX-87P column for mannose and galactose analysis (conditions: refractive index detector; flow rate of $0.6 \mathrm{~mL} /$ min at $85^{\circ} \mathrm{C} ; \mathrm{H}_{2} \mathrm{O}$ as mobile phase). The concentrations of sugars and acetic acid were employed to calculate the contents of cellulose and hemicellulose. The Klason lignin content was gravimetrically measured from the insoluble solid residue obtained after the quantitative acid hydrolysis. Analyses were carried out in triplicate. The analytical methods used in this work and the scheme of the whole process are shown in Fig. 1.

\subsection{Non-isothermal autohydrolysis pretreatment of the lignocellulosic mixtures (M1-4 and M2-3): solid and liquid phases composition}

The autohydrolysis pretreatment was performed in a $2 \mathrm{~L}$ stainless steel reactor (Parr Instruments Company, Moline, Illinois, USA) equipped with a Parr PID temperature controller (model 4848). Each sample (M1-4 or M2-3) was mixed at liquid to solid ratio (LSR) of $8 \mathrm{~kg}$ of water $/ \mathrm{kg}$ of oven-dry raw material. In autohydrolysis experiments, the reaction media was stirred at $150 \mathrm{rpm}$ and heated by an external jacket, following the standard heating temperaturetime profile to reach the desired maximum temperature, and the reactor was rapidly cooled-down through water recirculation by an internal loop (Fig. 2).

For each mixture, several non-isothermal conditions were tested, reaching final temperatures (TMAX) of 190, 196, 206, 216, 226 and $240{ }^{\circ} \mathrm{C}$ (pressure from 13 to 34 bar). The autohydrolysis experiments were carried out by duplicate. Once the target temperature was reached, the media were immediately cooled and filtered.

The intensity of autohydrolysis pretreatments can be expressed in terms of "severity" $\left(S_{0}\right)$, defined as the logarithm of $\mathrm{R}_{0}$ [16], which was calculated using the expression, Equation (1): Fig. 1- Flow chart of whole process and analytical methods used in this work. 
Table 1

Proportion of the two mixtures from lignocellulosic biomass stablished by quarter.

\begin{tabular}{|c|c|c|c|}
\hline \multirow[t]{2}{*}{ Type Lignocellulosic resources } & & \multicolumn{2}{|c|}{ Mixtures proportion (\%) } \\
\hline & & M1-4 & M2-3 \\
\hline \multirow[t]{3}{*}{ (A) forest ecosystems } & Pine (Pinus pinaster) & 16.6 & 24.6 \\
\hline & Eucalyptus (Eucalyptus globulus) & 18.8 & 27.9 \\
\hline & Total & 35.4 & 52.5 \\
\hline \multirow[t]{5}{*}{ (B) biological resources from marginal land } & broom (Cytisus sp.) & 18.8 & 13.8 \\
\hline & mimosa (Acacia dealbata) & 17.0 & 12.5 \\
\hline & carqueja (Genista tridentata) & 14.6 & 10.7 \\
\hline & rockrose (Cistus ladanifer) & 14.2 & 10.4 \\
\hline & Total & 64.6 & 47.5 \\
\hline
\end{tabular}

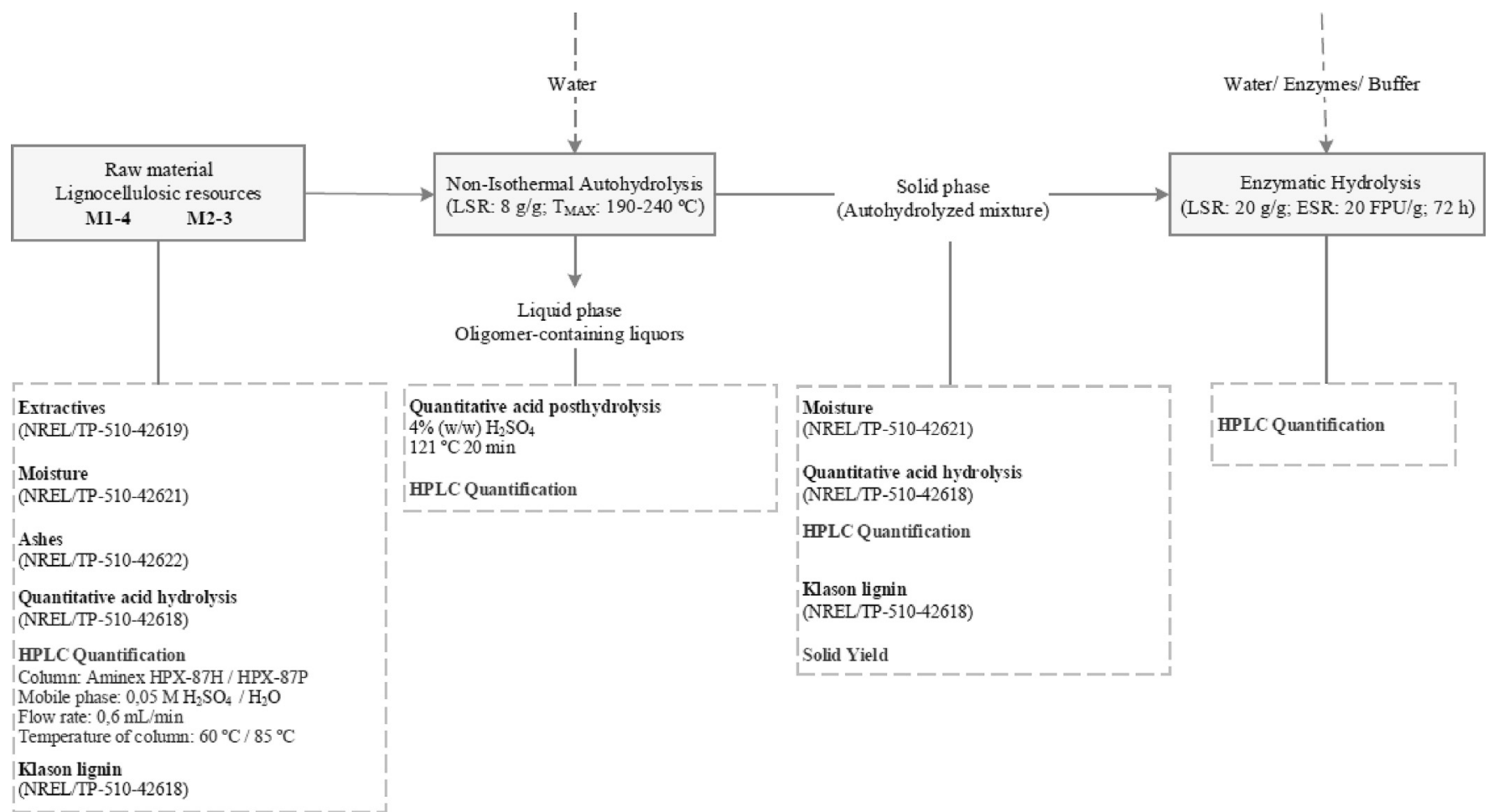

Fig. 1. Flow chart of whole process and analytical methods used in this work.

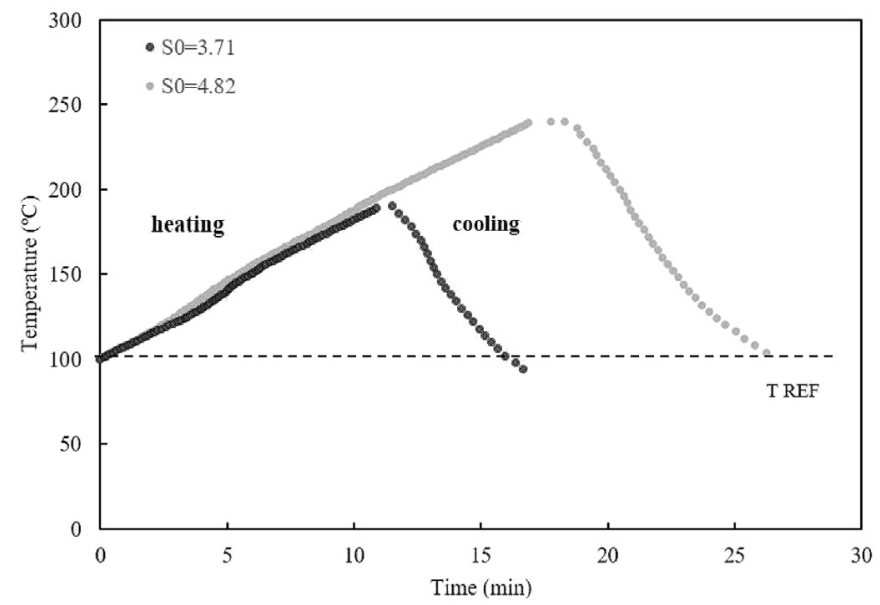

Fig. 2. Heating and cooling temperature profiles of autohydrolysis assay carried out at $\mathrm{S}_{0}=3.71$ and $4.82 . \mathrm{T}_{\mathrm{REF}}$ : temperature of reference, $100^{\circ} \mathrm{C}$.

$$
\begin{array}{r}
S_{0}=\log R_{0}=\log \left[R_{0 \text { HEATING }}+R_{0} \text { coolinG }\right] \\
=\log \left[\int_{0}^{t_{\text {MAX }}} \exp \left(\frac{T(t)-T_{R E F}}{\omega}\right) \mathrm{d} t\right] \\
+\log \left[\int_{0}^{t F} \exp \left(\frac{T^{\prime}(t)-T_{R E F}}{\omega}\right) \mathrm{d} t\right]
\end{array}
$$

According to this equation, $S_{0}$ includes the combined effects of temperature and reaction time along the periods of heating and cooling. In Eq. (1), $\mathrm{t}_{\mathrm{MAX}}(\mathrm{min})$ is the time needed to achieve $\mathrm{T}_{\mathrm{MAX}}$ $(\mathrm{K}), \mathrm{t}_{\mathrm{F}}(\mathrm{min})$ is the time needed for the whole heating-cooling period, whereas $T(t)$ and $T^{\prime}(t)$ represent the temperature profiles in heating and cooling (Fig. 2), respectively. Calculations were made assuming the values reported in literature for $\omega$ and $T_{\text {REF }}(14.75 \mathrm{~K}$ and $373.15 \mathrm{~K}$, respectively). The range of studied temperatures was $190^{\circ} \mathrm{C}$ to $240^{\circ} \mathrm{C}$ corresponding to severities $\left(\mathrm{S}_{0}\right)$ of 3.71 and 4.82 , respectively.

Operational conditions were evaluated to maximize the 
concentration of hemicellulose derived compounds in liquid fraction and to improve enzymatic susceptibility of the glucan present in solid fraction.

The solid fraction was washed with distilled water and used to measure the solid yield of the autohydrolysis stage (SY, kg autohydrolyzed mixture $/ 100 \mathrm{~kg}$ raw material, oven-dry basis) and analyzed for chemical composition as described in Section 2.2. An aliquot of autohydrolysis liquid phase was filtered through $0.2 \mu \mathrm{m}$ membranes and used for direct HPLC determination of glucose, xylose, arabinose, acetic acid, hydroxymethyl (HMF) and furfural (F), using the same method specified above. A second aliquot was subjected to quantitative acid posthydrolysis ( $4 \% \mathrm{w} / \mathrm{w}$ sulphuric acid at $121^{\circ} \mathrm{C}$ for $20 \mathrm{~min}$ ), filtered through $0.2 \mu \mathrm{m}$ membranes and analyzed in HPLC for oligosaccharides quantification.

\subsection{Enzymatic hydrolysis of solid fraction from autohydrolysis pretreatment}

Enzymatic hydrolysis (EH) of autohydrolyzed mixtures were carried out at $50{ }^{\circ} \mathrm{C}$ and $\mathrm{pH} 4.85(0.05 \mathrm{~N}$ sodium citrate buffer) in $100 \mathrm{~mL}$ Erlenmeyer flasks with $50 \mathrm{~mL}$ of volume in orbital agitation (150 rpm) using Cellic CTec2 (Novozymes, Bagsvaerd, Denmark). The enzyme activity was $120 \mathrm{FPU} / \mathrm{mL}$. (measured as described by Ghose [17]). The conditions employed were $5 \%$ of oven-dry autohydrolyzed mixtures, enzyme to substrate ratio, denoted as $\mathrm{ESR}=20 \mathrm{FPU} / \mathrm{g}$ autohydrolyzed mixture on dry basis. The reaction time of enzymatic hydrolysis ranged from $0 \mathrm{~h}$ to $72 \mathrm{~h}$. At selected times, samples were withdrawn from the media, centrifuged, filtered and analyzed by HPLC for glucose and cellobiose. The results achieved in the $\mathrm{EH}$ were expressed in terms of glucose yield $\left(\mathrm{Y}_{\mathrm{G}}\right)(\%)$, calculated using the following Equation (2):

$\% Y_{G=} \frac{[\text { Glucose }]+1.053[\text { Cellobiose }]}{1.111 \text { fBiomass }} 100$

where [Glucose] is the glucose concentration $(\mathrm{g} / \mathrm{L})$, [Cellobiose] is the cellobiose concentration $(\mathrm{g} / \mathrm{L})$, [Biomass] is the dry biomass (or $\mathrm{LCB})$ concentration $(\mathrm{g} / \mathrm{L}), f$ is cellulose fraction in dry biomass $(\mathrm{g} / \mathrm{g})$, the multiplication factor, 1.053 , converts cellobiose to equivalent glucose. In all experiments, cellobiose was not detected.

\subsection{Determination of higher heating values of autohydrolyzed mixture}

Samples of dried biomass were analyzed for Higher Heating Values (HHVs) using an automatic adiabatic bomb calorimeter (Parr calorimeter Type 6200), in accordance with Jessup et al. [18]. The interior surface of the bomb was washed with distilled water and collected in a beaker. The bomb washings were titrated with a standard sodium carbonate solution $(0.0709 \mathrm{~N})$.

\subsection{Statistical analysis}

Linear Discriminant Analysis (LDA) was computed using STATGRAPHICS Centurion XVI.I, with a significance level of 5\%. The sources of variation for the raw material composition were cellulose (as glucan), xylan, arabinan, acetyl groups, mannan and galactan (as hemicellulose), Klason lignin, ashes and extractives for M1-4 and M2-3.

\section{Results and discussion}

\subsection{Raw material mixture criteria}

Several lignocellulosic biomasses have been individually studied to be used as raw material for biorefineries, nonetheless, the availability, seasonality, variability, price volatility and storage of biomass supply may be the major constraints on the use of these raw materials [12,19]. In this work, the use of different biomass sources may overcome these problems. Thus, the analysis of availability, security supply and seasonality (based on fire prevention) of lignocellulosic biomasses in Portugal were considered for the mixture definition.

The total territorial area generating residues [14] within the work focus corresponds to $52.5 \%$ of forest ecosystems (A) and $47.5 \%$ of biological resources from marginal land (B). Since eucalyptus and pine are the main ecosystems in Portugal that generate residues with high potential for the biorefineries, these two species were selected to represent (A) [20]. Whereas their distribution is according to territorial area [14], where 725 thousands (46.9\%) of hectares correspond to pine and 820 thousands (53.2\%) of hectares to eucalyptus. Regarding (B), the selection criteria was based on total sugars content of broom (66.7\%), carqueja (51.7\%), mimosa (60.4\%) and rockrose (50.2\%) [1]. Based on the different criteria, two different mixtures, M1-4 and M2-3, were established taking into account the higher fire risk in Portugal during the summer months (2nd and 3rd quarters) and the importance of collecting biological resources from marginal land during winter months (1st and 4th quarters). In general, $60-70 \%$ of forest fires occurs in woods and uncultivated areas [1]. Therefore, Table 1 shows the final proportions of biomasses assembled for M1-4 and M2-3.

The consideration of feedstock mixtures have been previously studied only in few works $[12,21,22]$. In some of these cases, the criteria of mixture were based on the importance of these raw materials for the region, such as mixture of eucalyptus, wheat straw and olive tree pruning in Southern Europe, prepared in different combinations to be tested [12]. In other cases, the mixture was prepared in equivalent amounts (clover and ryegrass) [23] due to its importance in many agroecosystems [23], as well three relative proportions of wheat straw and clover-grass were studied [22]. Moreover, the consideration of more than one species of crops stands and/or forest feedstock supplemented with energy crops (such as switchgrass) to increase biomass yield have been previously studied by Jensen et al., where five species were mixed ( 50 / $50 \mathrm{wt} \%$ ) in 10 possible combinations [21].

\subsection{Chemical characterization of M1-4 and M2-3 mixtures}

Chemical characterization (Table 2) of the two mixtures proposed was carried out revealing a very similar composition, although the content of each fraction slightly varied according to the contribution of the predominant feedstock (described in Table 1).

\section{Table 2}

Chemical composition of feedstock mixtures (M1-4 and M2-3) (expressed in g/100 g of raw material in oven-dry basis \pm standard deviation on three replicate determinations).

\begin{tabular}{lll}
\hline Components & \multicolumn{2}{l}{ Feedstock mixtures } \\
\cline { 2 - 3 } & $\mathrm{M} 1-4$ & $\mathrm{M} 2-3$ \\
\hline Cellulose (as Glucan) & $34.17 \pm 1.14$ & $34.63 \pm 0.18$ \\
Hemicellulose & & \\
$\quad$ Xylan & $16.58 \pm 0.62$ & $17.48 \pm 0.45$ \\
Arabinan & $1.36 \pm 0.21$ & $1.27 \pm 0.03$ \\
Acetyl groups & $2.13 \pm 0.01$ & $1.95 \pm 0.29$ \\
Mannan & $3.19 \pm 0.03$ & $3.31 \pm 0.01$ \\
$\quad$ Galactan & $1.43 \pm 0.02$ & $1.26 \pm 0.03$ \\
Klason lignin & $30.05 \pm 0.00$ & $31.76 \pm 0.00$ \\
Ash & $1.29 \pm 0.08$ & $1.19 \pm 0.03$ \\
Extractives & $10.51 \pm 0.10$ & $9.23 \pm 0.31$ \\
\hline
\end{tabular}


Glucan was the polysaccharide found in higher amount and similar concentrations were found in both mixtures. Among the hemicellulose components, the xylan was found in the highest amount in the two mixtures, reaching $16.58 \mathrm{~g} / 100 \mathrm{~g}$ raw material of M1-4 and $17.48 \mathrm{~g} / 100 \mathrm{~g}$ raw material of M2-3.

Arabinan and acetyl groups were identified, although in lower proportions in both mixtures, approximately $2 \mathrm{~g} / 100 \mathrm{~g}$ raw material. Mannan showed concentration around $3 \mathrm{~g} / 100 \mathrm{~g}$ raw material for both mixtures and galactan was detected in low concentrations approximately $1 \mathrm{~g} / 100 \mathrm{~g}$ raw material. Klason lignin was the second highest fraction in the mixtures, namely $30 \%$ for $\mathrm{M} 1-4$ and $32 \%$ for M2-3. Ashes were quantified and correspond to about $1 \%$ for both mixtures. Extractives correspond approximately to $10 \%$ in both mixtures. As seen in Table 2, there were no significant differences regarding chemical composition between M1-4 and M2-3 ( $p$ value $>0.05$ ).

Nevertheless, the study of mixture of different species is still scarce. Previous reports already studied the species that compose M1-4 and M2-3 individually, namely, Acacia dealbata [24], Cytisus sp. [25], Pinus pinaster [5] and Eucalyptus globulus [26]. In these studies, the cellulose content (as glucan) was higher than $40 \%$, while M1-4 and M2-3 presented lower content of cellulose, around 35\%. This fact can be explained due to extractives content, as the mixtures comprised branches and twigs with bark and leaves [27], since the aim of this work was the integral valorization of these lignocellulosic resources.

Despite the similar composition of M1-4 and M2-3, the outcome of pretreatment could be different due to their diverse origin (hardwood, softwood and bush), making it necessary to analyze the pretreatment effect on both mixtures.

\subsection{Effect of autohydrolysis pretreatment on fractionation of M1- 4 and M2-3 mixtures}

The conditions of pretreatment $\left(190^{\circ} \mathrm{C}\right.$ to $\left.240^{\circ} \mathrm{C}\right)$ were chosen based on reported data by Romaní et al. [9] and Silva-Fernandes et al. [12]. For integral valorization of biomass, all fractions should be considered [3]. Thus, in this work, fractionation of two mixtures was evaluated in order to recover the hemicellulose as oligosaccharides and to improve the enzymatic saccharification of cellulose and/or use the solid fraction as solid biofuel.

\subsubsection{Solid phase composition after autohydrolysis pretreatment}

Chemical composition of solid phase after autohydrolysis pretreatment is shown in Table 3. The solid yield (SY) decreased with severity increase and varied from 62.37 to $75.25 \mathrm{~g} / 100 \mathrm{~g}$ raw material for M1-4 and $62.33-76.70 \mathrm{~g} / 100 \mathrm{~g}$ raw material for $\mathrm{M} 2-3$, which is in agreement with previous works under similar conditions for other hardwoods $[11,26]$.

The glucan content varied in the range of $40.96-47.00 \mathrm{~g}$ glucan/ $100 \mathrm{~g}$ autohydrolyzed mixture (on dry basis) for pretreated M1-4 and $41.07-48.47 \mathrm{~g}$ glucan $/ 100 \mathrm{~g}$ autohydrolyzed mixture (on dry basis) for pretreated M2-3. Thus, the percentage of glucan that remained in the solid fraction was very similar after pretreatment for both mixtures, presenting an average of glucan recovery about $84.86 \%$ and $88.68 \%$ (expressed as $\mathrm{g}$ of glucan per $100 \mathrm{~g}$ of autohydrolyzed mixture) for M1-4 and M2-3, respectively, which reveals the selectivity of this pretreatment.

In addition, the content of lignin after pretreatment varied in the range of $35.76-47.82$ and $37.04-44.56 \mathrm{~g}$ lignin $/ 100 \mathrm{~g}$ autohydrolyzed mixture of M1-4 and M2-3, respectively. The average recovery was high for the two mixtures, $96.36 \%$ and $90.36 \%$ (expressed as $\mathrm{g}$ of lignin per $100 \mathrm{~g}$ of autohydrolyzed mixture) for M1-4 and M2-3, respectively.

However, lignin content followed a typical pattern for both

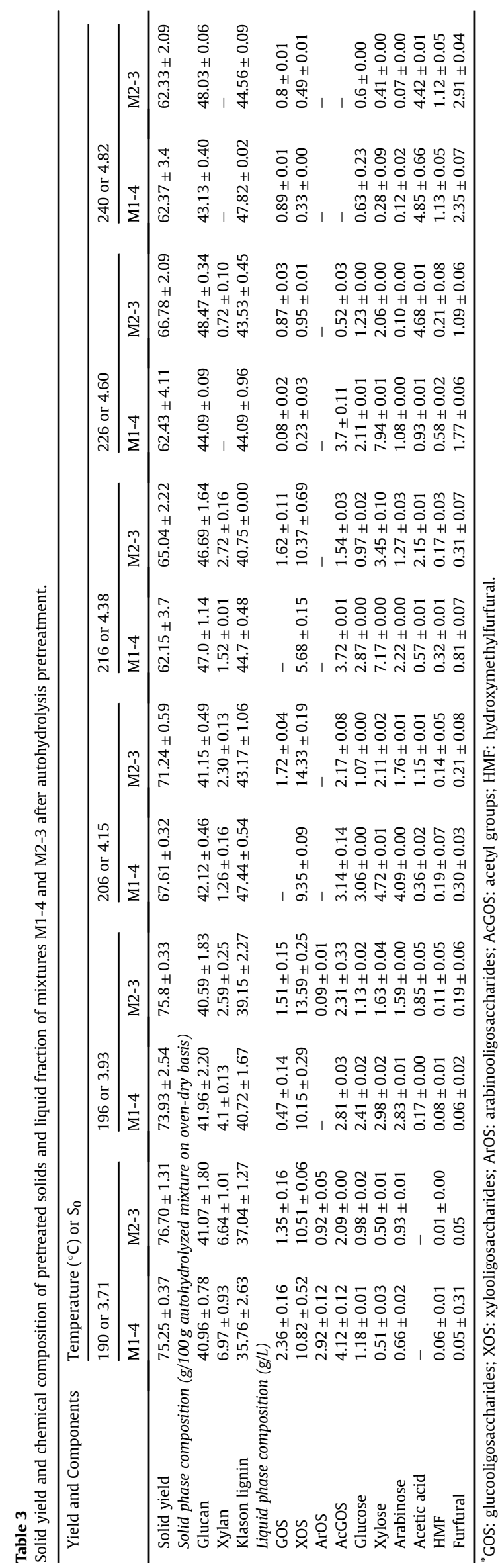


mixtures, up to a temperature of $206^{\circ} \mathrm{C}$ the remaining lignin in the solid fraction increased, from this temperature forward, lignin content decreased and it increased again under the most severe condition $\left(240^{\circ} \mathrm{C}\right)$. This behavior was also studied by Moniz et al. with autohydrolyzed rice straw where until $210^{\circ} \mathrm{C}$ the remaining lignin was close to $100 \%$ of the initial amount, from $210^{\circ} \mathrm{C}$ onwards showed a decreased around $30 \%$ and it increased again for the most severe conditions [28]. The lignin increase is common of autohydrolysis pretreatment due to condensation reactions between lignin, sugars and degradation products (HMF and F) leading to the formation of insoluble compounds that are quantified as Klason lignin $[9,29]$.

Under most severe conditions $\left(\mathrm{S}_{0}=4.15\right)$ glucan and lignin represent more than $84 \%$ of the solid fraction, and the combined amounts of these fractions matched the one contained in the raw material. These results are comparable with the results obtained by Silva-Fernandes et al. in which at the same conditions glucan and lignin contain $85 \%$ of the solid fraction [12].

The hemicellulose in the pretreated mixtures, namely, xylan showed a steadily decrease with the severity of pretreatment and it was the most solubilized fraction, since it was totally solubilized for both mixtures at temperatures higher than $226^{\circ} \mathrm{C}$. The same was reported by Silva-Fernandes et al. in which under most severe conditions $93-95 \%$ of xylan was solubilized in liquid phase [12]. Patel et al. studied a different pretreatment (dilute acid pretreatment) to solubilize the hemicellulose fraction in which revealed that almost, all the hemicellulose content was hydrolyzed, obtained only $0.4 \%$ in the solid fraction. However, this pretreatment is not ecofriendly, since it requires an additional detoxification step, increasing the process cost [13].

The data described above indicate that autohydrolysis pretreatment is an appropriate process for the selective fractionation of both mixtures in which showed high hemicellulose solubilization, directly proportional to autohydrolysis severity, while cellulose and lignin were usually retained in the solid fraction.

\subsubsection{Composition of liquid phase resulting from autohydrolysis pretreatment}

Autohydrolysis process allows substantial fractionation of components, namely oligosaccharides, monosaccharides, acetyl groups from hemicellulose, and degradation products of released sugars as furfural (F) and hydroxymethylfurfural (HMF).

The liquid phase composition of the two mixtures (M1-4 and M2-3) is presented in Table 3, in which the products recovered were represented in three groups: oligosaccharides (OS), including glucooligosaccharides (GOS), xylooligosaccharides (XOS), arabinooligosaccharides (ArOS) and acetyl groups (AcGOS); monosaccharides, as well as glucose, xylose and arabinose; and other byproducts such as organic acids (acetic acid) and furans (HMF and F).

Based on the previous reports [9], the concentrations (in g/L) of the liquid phase derived principally from hemicellulose fractions. Hence, the main compounds were XOS and xylose. The maximal XOS concentrations $(10.8 \mathrm{~g} / \mathrm{L}$ and $14.3 \mathrm{~g} / \mathrm{L})$ were obtained at $190{ }^{\circ} \mathrm{C}$ and $206{ }^{\circ} \mathrm{C}$ for M1-4 and M2-3, respectively, representing $47.7 \%$ and $58.1 \%$ of the total compounds presented in the liquid phase. Therefore, at these conditions of autohydrolysis pretreatment, $47.4 \%$ and $59.8 \%$ of xylan solubilization was recovered as XOS for M1-4 and M2-3, respectively. These results can be compared with reported data in literature using single biomass as fast-growing Paulownia hardwood in which $60 \%$ of the identified compounds in the liquid phase were XOS, achieved at $S_{0}$ of 3.99 [11], and using a mixture of biomasses (eucalyptus, wheat straw and olive pruning) in which $63-68 \%$ of xylan was recovered as xylooligosaccharides [12]. In addition, higher xylose concentration was obtained from the hydrothermal treatment of mixture of lignocelluosic materials (Bermuda grass, Jasmine hedges and Date palm fronds) at $200^{\circ} \mathrm{C}$ than individual treatment of lignocellulosic biomasses (Bermuda grass or Date palm fronds) [13]. Nevertheless, direct comparison with the literature is not straightforward since composition and nature of biomass sources are not same.

At more severe conditions $\mathrm{S}_{0}>4.15$ the concentration of XOS decreased until reached $0.33 \mathrm{~g} / \mathrm{L}$ and $0.49 \mathrm{~g} / \mathrm{L}$ for M1-4 and M2-3, respectively. XOS started to degrade into xylose, in which M1-4 achieved $7.9 \mathrm{~g} / \mathrm{L}$ of maximal xylose concentration at $226{ }^{\circ} \mathrm{C}$ $\left(\mathrm{S}_{0}=4.60\right)$ and $\mathrm{M} 2-3$ obtained $3.5 \mathrm{~g} / \mathrm{L}$ at $\mathrm{S}_{0}=4.38$.

The highest xylan solubilization as a sum of xylose and XOS (62.2\% and $68.6 \%$ for M1-4 and M2-3, respectively) was obtained at $\mathrm{T}_{\mathrm{MAX}}=206^{\circ} \mathrm{C}$ for both mixtures. This result is consistent with Romaní et al. [9] in which, at mild conditions $\left(\mathrm{T}_{\mathrm{MAX}}=210^{\circ} \mathrm{C}\right) 76 \%$ of xylan can be recovered as xylose and XOS.

Consequently, the highest furfural concentration was $2.5 \mathrm{~g} / \mathrm{L}$ for M1-4 and $2.9 \mathrm{~g} / \mathrm{L}$ at $\mathrm{S}_{0}=4.16$. The highest HMF concentration was also found at the same severity, in which $1.1 \mathrm{~g} / \mathrm{L}$ was obtained for both mixtures. Acetic acid raised the maximum at $\mathrm{S}_{0}>3.94$ of $4.7 \mathrm{~g} /$ $\mathrm{L}$ and $4.9 \mathrm{~g} / \mathrm{L}$ for M1-4 and M2-3, respectively. The harsher conditions of pretreatment led to an increase of inhibitor compounds, as $\mathrm{F}, \mathrm{HMF}$, and acetic acid. The concentration of $\mathrm{F}$ is higher than HMF, because the first is attributed to the degradation of xylose while

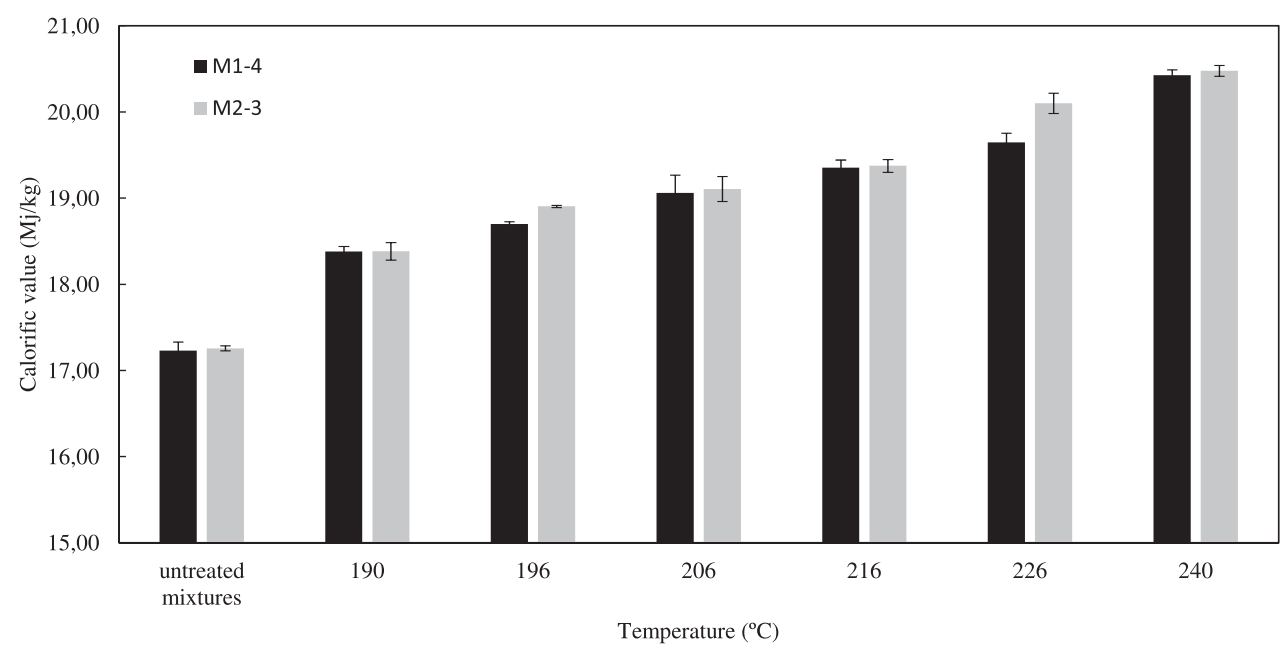

Fig. 3. Calorific value $(\mathrm{MJ} / \mathrm{kg})$ of raw material and pretreated biomasses (M1-4 and $\mathrm{M} 2-3$ ) at different $\mathrm{T}_{\mathrm{MAX}}$. 


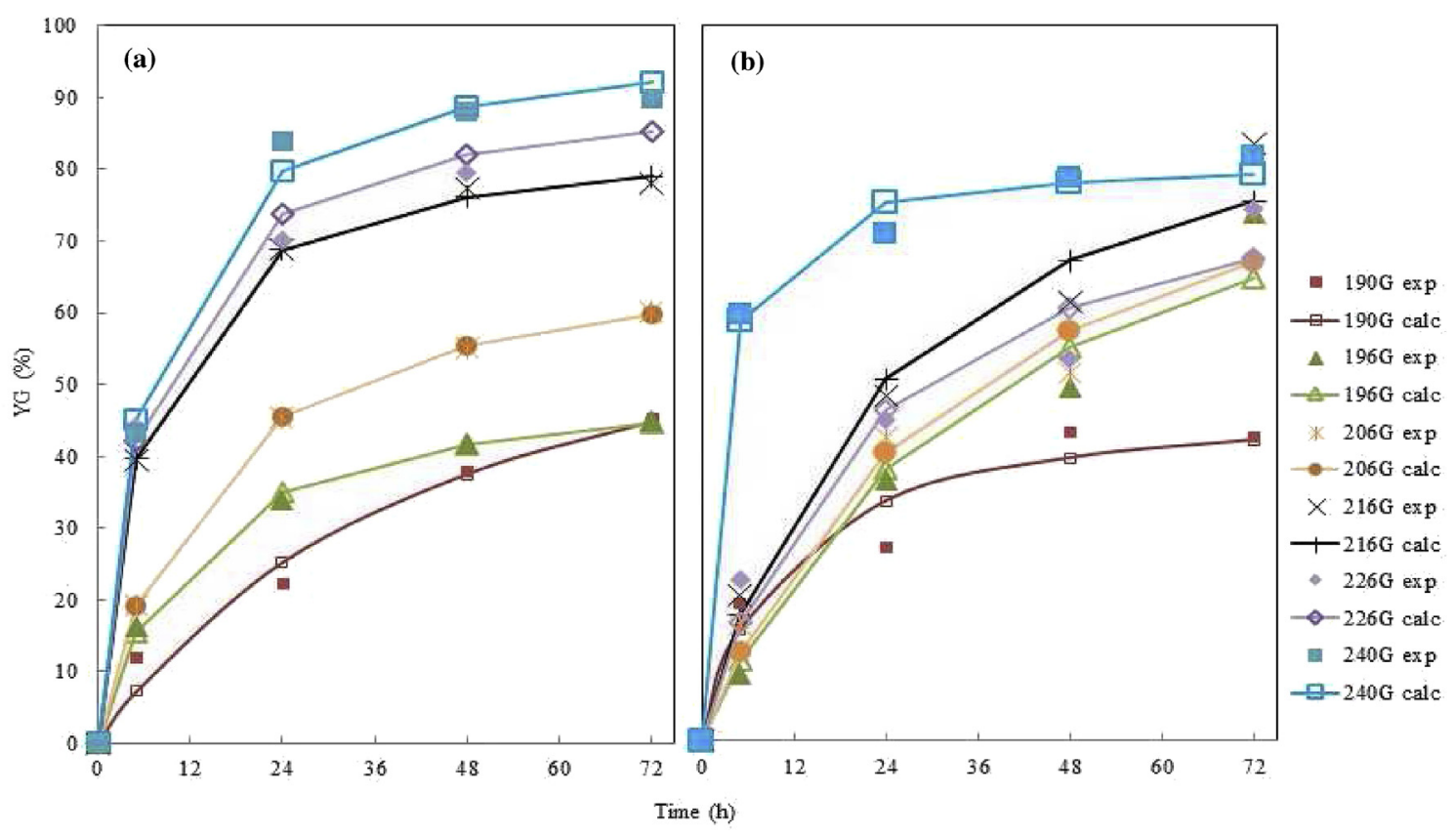

Fig. 4. Yield of glucose $Y_{G}(\%)$ at autohydrolysis conditions ( $\left.T_{M A X}\right)$ in the range $190^{\circ} \mathrm{C}$ to $240^{\circ} \mathrm{C}$ for $\mathrm{M} 1-4$ (a) and $\mathrm{M} 2-3$ (b).

HMF is obtained through C6 degradation, namely glucose.

As mentioned before, glucose was also present in low amounts varying between 0.6 and $3.1 \mathrm{~g} / \mathrm{L}$ for M1-4 and $0.6-1.2 \mathrm{~g} / \mathrm{L}$ for M2-3, which represented on average $3.6 \%$ of glucan solubilization for M14 and $1.7 \%$ for M2-3. The results obtained in this work are in agreement with reported data using Paulownia tomentosa wood in which $<4 \%$ of glucan was recovered in liquid phase [11]. As seen in Table 3, M1-4 and M2-3 showed differences in XOS and xylose concentration. This fact was probably influenced by the intrinsic features of lignocellulosic biomass, since M1-4 is composed by a higher percentage of residues from bush (as broom, mimosa, carqueja and rockrose) than M2-3. Besides oligosaccharides, sugar degradation products, acetic acid, extractives and phenolic compounds are also solubilized to liquid phase (or autohydrolysis liquor) during hydrothermal treatment [30]. The presence of these non-saccharide compounds in the hydrolysate decreased the purity of xylooligosaccharides which should be removed by physical and/or chemical means [31]. The difference observed between the two lignocellulosic mixtures could be related to a higher percentage of extractives in M1-4 than M2-3. In fact, the solubilized fraction (calculated as 100-SY) during the autohydrolysis treatment was higher in M1-4 than M2-3 (Table 3) showing differences in their fractionation. The main fractions recovered in the liquid phase, xylose and XOS, can be used for value-added compounds production as xylitol, lactic acid and ethanol obtained by fermentation and/or directly as prebiotic [32-34].

As previously reported, at $\mathrm{T}_{\mathrm{MAX}}=206^{\circ} \mathrm{C}$, high percentages of hemicellulose were removed but also primary degradation products (F and HMF) were kept at relatively low levels, which could be achieved by applying pretreatment conditions of moderate severity. Although pretreatment improves enzymatic access to cellulose for further fermentation, it generates byproducts decomposition which may affect negatively fermentation [35].

\subsection{Energy production of pretreated M1-4 and M2-3 mixtures}

HHVs of pretreated mixtures were analyzed in order to evaluate the influence of pretreatment and compare their behavior as solid fuel. These results are displayed in Fig. 3. The untreated mixtures were analyzed and showed HHVs of $17.23 \mathrm{MJ} / \mathrm{kg}$ and $17.26 \mathrm{MJ} / \mathrm{kg}$ for M1-4 and M2-3, respectively. HHV of pretreated samples increased with severity, achieving maximal values of $20.4 \mathrm{MJ} / \mathrm{kg}$ and $20.5 \mathrm{MJ} /$ $\mathrm{kg}$, for M1-4 and M2-3, respectively. The results obtained in this work are in agreement with reported data using softwood chips in which the HHV of the original wood was $17.9 \mathrm{MJ} / \mathrm{kg}$ and with temperature increase (autohydrolysis pretreatment) reached $20.5 \mathrm{MJ} / \mathrm{kg}$ [36]. Leaching processes with water and acetic acid were also used to increase the HHVs of six different biomasses (fast growing timber species and oil pal biomass), achieving values in the range of $16.52-18.47 \mathrm{MJ} / \mathrm{kg}$ [37].

This behavior is related to the increase of lignin content in the samples (Table 3) as a consequence of temperature rise, since lignin presents higher calorific value $(20.4 \mathrm{MJ} / \mathrm{kg})$ than cellulose $(16.5 \mathrm{MJ} /$ $\mathrm{kg})$ and hemicellulose $(13.9 \mathrm{MJ} / \mathrm{kg})[36,38]$. The HHVs are higher for raw materials as hardwoods and softwoods than for non-wood biomass being linearly related with lignin content [39].

The HHV obtained in this work showed suitability of these mixtures as solid biofuels when compared with other biomasses

Table 4

Glucose concentration, $\mathrm{G}_{72}$, and glucose yield, $\mathrm{Y}_{\mathrm{G} 72}$, at reaction time of $72 \mathrm{~h}$, maximal glucose yield, $Y_{\mathrm{GMAX}}$, time needed to achieve $1 / 2$ of $\mathrm{Y}_{\mathrm{GMAX}}, \mathrm{t}_{1 / 2}$ and coefficient of determination $\mathrm{R}^{2}$.

\begin{tabular}{lllllll}
\hline $\mathrm{T}_{\mathrm{MAX}}\left({ }^{\circ} \mathrm{C}\right) / \mathrm{S}_{0}$ & Substrate & $\mathrm{G}_{72}(\mathrm{~g} / \mathrm{L})$ & $\mathrm{Y}_{\mathrm{G} 72}(\%)$ & $\mathrm{Y}_{\mathrm{GMAX}}(\%)$ & $\mathrm{t}_{1 / 2}(\mathrm{~h})$ & $\mathrm{R}^{2}$ \\
\hline \multirow{2}{*}{190 or 3.71} & M1-4 & 10.04 & 45.30 & 73.21 & 45.68 & 0.98 \\
& M2-3 & 9.44 & 42.46 & 48.15 & 10.47 & 0.95 \\
196 or 3.93 & M1-4 & 10.26 & 45.09 & 51.86 & 11.67 & 1.00 \\
& M2-3 & 16.21 & 73.70 & 100.0 & 39.11 & 0.96 \\
206 or 4.15 & M1-4 & 13.81 & 60.18 & 71.08 & 13.54 & 1.00 \\
& M2-3 & 16.47 & 73.72 & 100.0 & 35.61 & 0.97 \\
216 or 4.38 & M1-4 & 19.91 & 77.97 & 85.33 & 5.77 & 1.00 \\
& M2-3 & 21.15 & 85.54 & 100.0 & 23.45 & 0.97 \\
226 or 4.60 & M1-4 & 21.51 & 89.82 & 92.26 & 5.98 & 0.99 \\
& M2-3 & 19.59 & 74.43 & 87.26 & 21.25 & 0.96 \\
240 or 4.82 & M1-4 & 21.11 & 89.94 & 99.87 & 6.07 & 1.00 \\
& M2-3 & 21.34 & 81.78 & 81.28 & 1.93 & 0.99 \\
\hline
\end{tabular}




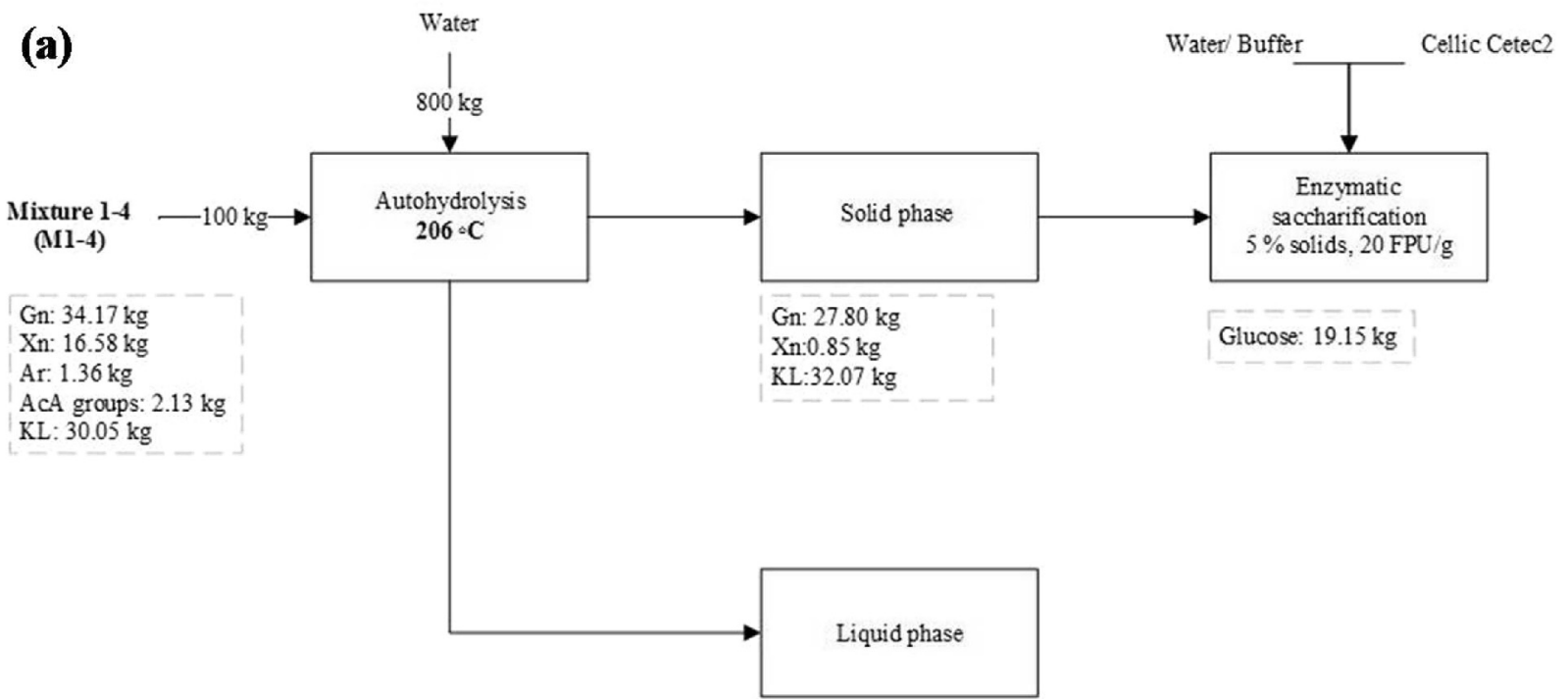

(b)
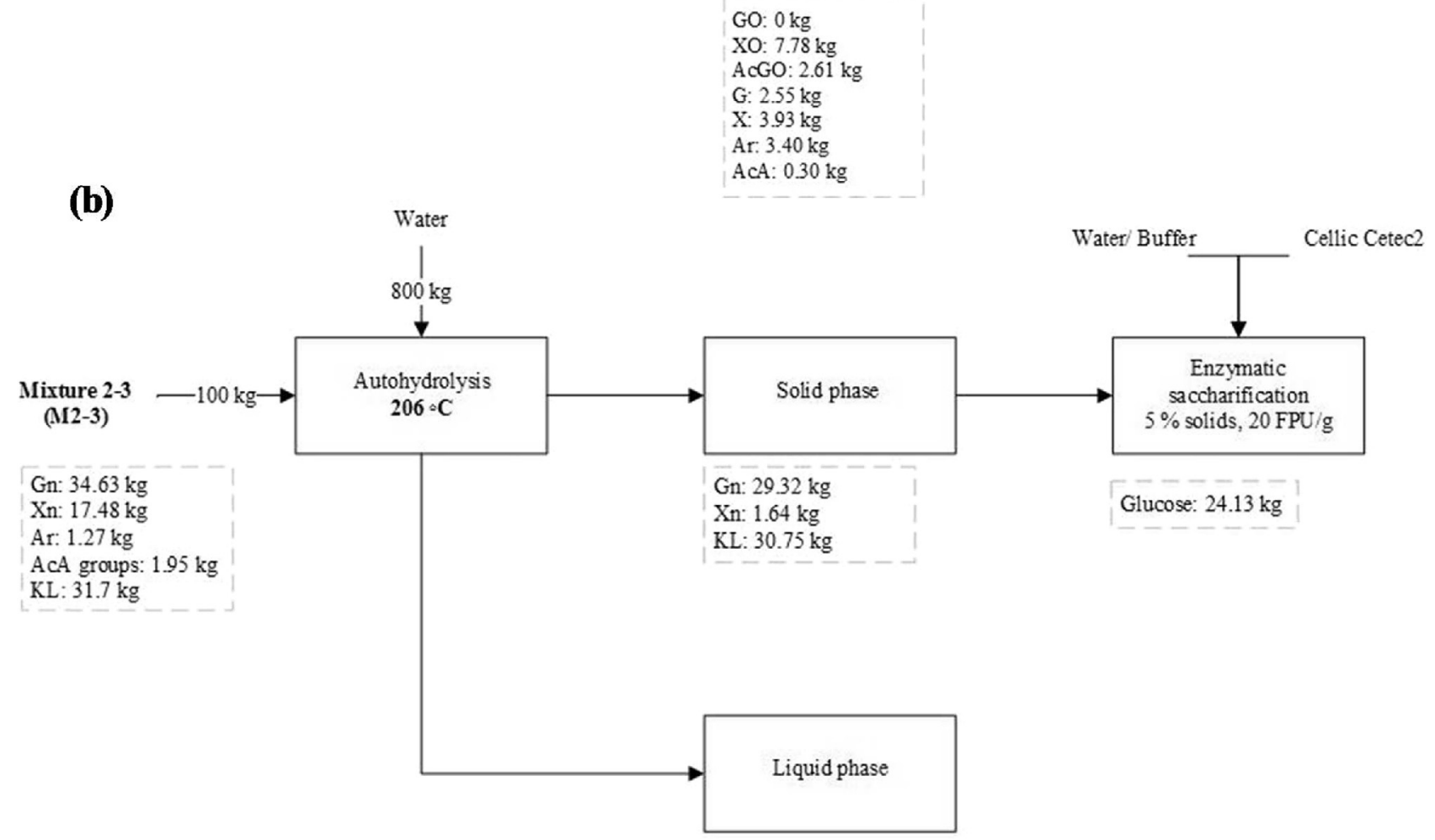

GO: $1.43 \mathrm{~kg}$

XO: $11.88 \mathrm{~kg}$

ACGO: $1.80 \mathrm{~kg}$

G: $0.89 \mathrm{~kg}$

$\mathrm{X}: 1.75 \mathrm{~kg}$

Ar. $1.46 \mathrm{~kg}$

AcA: $0.95 \mathrm{~kg}$

Fig. 5. Overall balance of M1-4 (a) and M2-3 (b) for autohydrolysis and saccharification processing at $\mathrm{T}_{\mathrm{MAX}}=206{ }^{\circ} \mathrm{C}$ (results expressed in $\mathrm{kg} / 100 \mathrm{~kg}$ raw material) oven dry basis.

[40]. Nevertheless the use of these mixtures as solid biofuel for energy content in combustion process or the alternative use as glucose source, for liquid biofuels production should be carefully analyzed and evaluated, in order to the overall net benefit [36].

\subsection{Enzymatic saccharification of pretreated M1-4 and M2-3 mixtures}

Two mixtures of pretreated lignocellulosic biomass by autohydrolysis were also suitable for glucose production, the main carbon 
source to produce several industrial products (as bioethanol and chemicals). Thus, cellulosic fraction can be saccharified for sugar production using enzymes. Autohydrolysis pretreatment improves the enzymatic saccharification due to the structural alteration, as result of hemicellulosic fraction solubilization. In this sense, the solid fraction obtained from autohydrolysis was used as substrate in the assays of enzymatic hydrolysis in order to evaluate the susceptibility of pretreated biomass for glucose production. Time course of glucose yield for the two mixtures in the selected autohydrolysis conditions studied in this work $\left(\mathrm{S}_{0}: 3.71-4.82\right)$ is displayed in Fig. 4 (a) and (b). As seen in Fig. 4, kinetics of enzymatic hydrolysis followed a typical pattern. Therefore, values of glucose yield obtained from enzymatic hydrolysis in this set of experiments were fitted to the Holtzapple empirical equation (3) [41]:

$Y_{G t}=Y_{G M A X} \times \frac{t}{t+t_{1 / 2}}$

where $\mathrm{Y}_{\mathrm{Gt}}$ is the glucose yield at time $t, \mathrm{Y}_{\mathrm{GMAX}}$ is the maximum glucose yield achievable at infinite reaction time, and $t_{1 / 2}(\mathrm{~h})$ measures the reaction time needed to reach $50 \%$ of glucose yield.

The representation of calculated and experimental data (Fig. 4) and the values of $\mathrm{R}^{2}$ (Table 4 ) showed the goodness of adjustment to the empirical model. These results showed that the severity of pretreatment increased the glucose yield and reduced the time of hydrolysis. The reaction time needed to reach $50 \%$ of glucose yield $\left(\mathrm{t}_{1 / 2}\right)$ was lower for M1-4 than for M2-3, in all the cases, except for the lowest $\left(190^{\circ} \mathrm{C}\right)$ and highest $\left(240^{\circ} \mathrm{C}\right) \mathrm{T}_{\text {MAX. }}$. As evident in Fig. 4 , the harshness of pretreatment had a positive effect on the susceptibility of pretreated biomass to enzymatic hydrolysis. Glucose yield increased from $45.30 \%$ to $89.94 \%$ and from $42.46 \%$ to $81.78 \%$, for M1-4 and M2-3, respectively, at $72 \mathrm{~h}$ of enzymatic hydrolysis (Table 4). Considering only autohydrolyzed Eucalyptus globulus wood, Romaní et al. [42] reported a glucose yield of $100 \%$ at $\mathrm{T}_{\mathrm{MAX}}>$ $210^{\circ} \mathrm{C}$

There was a greater difference of glucose yield at $\mathrm{T}_{\text {MAX }} 196^{\circ} \mathrm{C}$ between M1-4 (45.09\%) and M2-3 (73.70\%) at $72 \mathrm{~h}$. On the other hand, M1-4 reached glucose yield higher than M2-3 at $\mathrm{T}_{\text {MAX }}>$ $226^{\circ} \mathrm{C}$.

An increase in the autohydrolysis severity $\left(\mathrm{S}_{0}\right)$ from 3.71 to 4.82 allowed glucose concentration to increase from $10 \mathrm{~g} / \mathrm{L}$ to $21 \mathrm{~g} / \mathrm{L}$, approximately, at $72 \mathrm{~h}$ of hydrolysis for the two mixtures (Table 4). The similar behavior was reported by Domínguez et al. [11], using Paulownia tomentosa as biomass, where an increase in the autohydrolysis severity from $S_{0} 3.31$ to 4.82 allowed a five-fold increment in glucose concentration to $27.5 \mathrm{~g} / \mathrm{L}$ at $120 \mathrm{~h}$.

In general, enzymatic hydrolysis is an efficient process without generation of any toxic waste and does not contain fermentation inhibitors, which reveals a promising strategy to obtain higher glucose yield [43].

\subsection{Overall balance of M1-4 and M2-3}

Considering the results obtained in this study, Fig. 5 compares the fractionation effect of autohydrolysis pretreatment on the two feedstock mixtures. The highest hemicellulose solubilization (as XOS and xylose) was observed at $\mathrm{T}_{\mathrm{MAX}}=206^{\circ} \mathrm{C}$, as glucose yield of enzymatic hydrolysis higher than $60 \%$ for both mixtures (Table 4 ). As seen in Fig. 5, the value-added compound obtained in separated streams was of $19.1 \mathrm{~kg}$ of glucose for M1-4 and $24.1 \mathrm{~kg}$ of glucose for M2-3. Overall yield of glucose for M1-4 and M2-3 was 50\% and 63\%, respectively. These results can be compared with reported data in literature using the same pretreatment, in which $76 \%$ and $63 \%$ of glucose yield at $S_{0}=4.13$ were achieved from brewers's spent grain and corn husk, respectively [44]. At the same condition, overall yield of xylose was $62 \%$ and $69 \%$ for M1-4 and M2-3, respectively. The results obtained for xylose yield can be favorably compared with data reported by Nitsos et al., that obtained around 60\% yield ( $\left.\mathrm{S}_{0} 3.8-4.01\right)$ for poplar and grapevine, respectively [19]. The data described above indicate that autohydrolysis at $206^{\circ} \mathrm{C}$ is an appropriate process for the selective fractionation of mixtures obtaining a solid fraction composed mainly by glucan and lignin, and high solubilization of hemicellulose into the liquid phase with minimum formation of degradation products. Cellulose was subjected to enzymatic hydrolysis and could be further processed for biological conversion into biofuels, biochemical or biomaterials as single or in combination with sugars obtained from liquid phase. The remaining lignin can simply be used for co-generation of energy in a biorefinery context or exploited for other high value applications.

\section{Conclusions}

This work provides a comparative study of two biomass mixtures in order to supply a lignocellulosic biorefinery throughout the year, showing a suitable solution for the utilization and valorization of forest and marginal land resources in Portugal. Autohydrolysis was used for the fractionation of these biomass mixtures, showing differences on hemicellulose solubilization and enzymatic hydrolysis of cellulose into glucose. Nevertheless, under selected conditions, maximal hemicellulose recovery as xylooligosaccharides and xylose was achieved for two mixtures, allowing to operate at same conditions independently of selected biomass mixture. The proposed multi-supply raw materials biorefinery increases the sustainability of the value chain, in terms of the biomass (not pressure in same renewable resources) and avoids forest fires. In addition, an environmentally-friendly pretreatment is used for the fractionation of multi supply biomass in order to coproduce solid biofuels, oligosaccharides and glucose which may be further converted to liquid biofuels or to platform chemicals.

\section{Acknowledgments}

This study was supported by the Portuguese Foundation for Science and Technology (FCT) under the scope of the strategic funding of UID/BIO/04469/2013 unit and COMPETE2020 (POCI-010145-FEDER-006684/ POCI-01-0145-FEDER-007440), the BioTecNorte operation (NORTE-01-0145-FEDER-000004) funded by European Regional Development Fund under the scope of Norte2020 - Programa Operacional Regional do Norte and the MultiBiorefinery project (POCI-01-0145-FEDER-016403). Rita Pontes (SFRH/BDE/109316/2015) and Michele Michelin (SFRH/BPD/ 100786/2014) thank FCT for their doctoral and postdoctoral fellowships, respectively.

\section{References}

[1] G.V. Duarte, A.I. Moura, R. Moreira, J. Nunes, M.M. Figueiredo, M.G. Carvalho, Evaluation of several forest residues as potential raw material for bioethanol production in Portugal, J. Bioprocess Eng. Biorefinery 2 (2013) 73-78.

[2] J. Nunes, J. Fierro, H. Freitas, Sustainable management of forest ecosystems and lignocellulosic biomass use: a case study from Portugal, in: 20th European Biomass Conference and Exhibition, 2012.

[3] P. Gullón, A. Romaní, C. Vila, G. Garrote, J.C. Parajó, Potential of hydrotherma treatments in lignocellulose biorefineries, Biofuels Bioprod. Biorefining 6 (2012) 219-232.

[4] F. Cherubini, The biorefinery concept: using biomass instead of oil for producing energy and chemicals, Energy Convers, Manag 51 (2010) 1412-1421.

[5] M.J. González-Muñoz, R. Alvarez, V. Santos, J.C. Parajó, Production of hemicellulosic sugars from Pinus pinaster wood by sequential steps of aqueous extraction and acid hydrolysis, Wood Sci. Technol. 46 (2012) 271-285.

[6] H.A. Ruiz, D.S. Ruzene, D.P. Silva, F.F.M. Da Silva, A.A. Vicente, J.A. Teixeira, Development and characterization of an environmentally friendly process sequence (autohydrolysis and organosolv) for wheat straw delignification, 
Appl. Biochem. Biotechnol. 164 (2011) 629-641.

[7] I.A. Ares-Peón, A. Romaní, G. Garrote, J.C. Parajó, Invasive biomass valorization: environmentally friendly processes for obtaining second generation bioethanol and saccharides from Ulex europaeus, J. Chem. Technol. Biotechnol. 88 (2013) 999-1006.

[8] A. Roman, A. Ruiz, F.B. Pereira, J.A. Teixeira, Fractionation of Eucalyptus globulus wood by glycerol - water pretreatment: optimization and modeling, Ind. Eng. Chem. Res. 52 (2013) 14342-14352.

[9] A. Romaní, G. Garrote, J.L. Alonso, J.C. Parajó, Bioethanol production from hydrothermally pretreated Eucalyptus globulus wood, Bioresour. Technol. 101 (2010) 8706-8712.

[10] Y. Xu, K. Zhang, D. Wang, High gravity enzymatic hydrolysis of hydrothermal and ultrasonic pretreated big bluestem with recycling prehydrolysate water, Renew. Energy 114 (2017) 351-356.

[11] E. Domínguez, A. Romaní, L. Domingues, G. Garrote, Evaluation of strategies for second generation bioethanol production from fast growing biomas Paulownia within a biorefinery scheme, Appl. Energy 187 (2017) 777-789.

[12] T. Silva-Fernandes, L.C. Duarte, F. Carvalheiro, M.C. Loureiro-Dias, C. Fonseca, F. Gírio, Hydrothermal pretreatment of several lignocellulosic mixtures containing wheat straw and two hardwood residues available in Southern Europe, Bioresour. Technol. 183 (2015) 213-220.

[13] H. Patel, D. Chapla, A. Shah, Bioconversion of pretreated sugarcane bagasse using enzymatic and acid followed by enzymatic hydrolysis approaches for bioethanol production, Renew. Energy 109 (2017) 323-331.

[14] ICNF, IFN6- Áreas dos usos do solo e das espécies florestais de Portugal continental, in: I.d.C.d.N.e.d. Florestas (Ed.), Resultados Preliminares, 2013. Lisboa.

[15] K. Karimi, M.J. Taherzadeh, A critical review of analytical methods in pretreatment of lignocelluloses: composition, imaging, and crystallinity, Bioresour. Technol. 200 (2016) 1008-1018.

[16] J.-M. Lavoie, E. Capek-Menard, H. Gauvin, E. Chornet, Production of pulp from Salix viminalis energy crops using the FIRSST process, Bioresour. Technol. 101 (2010) 4940-4946.

[17] T.K. Ghose, Measurement of cellulase activities, pac 59 (1987) 257.

[18] R.S. Jessup, Precise Measurement of Heat of Combustion with a Bomb Calorimeter, U.S. Department of Commerce, National Bureau of Standards, 1960.

[19] C.K. Nitsos, T. Choli-Papadopoulou, K.A. Matis, K.S. Triantafyllidis, Optimization of hydrothermal pretreatment of hardwood and softwood lignocellulosic residues for selective hemicellulose recovery and improved cellulose enzymatic hydrolysis, ACS Sustain. Chem. Eng. 4 (2016) 4529-4544.

[20] J.M.d.S.A. Nunes, Modelo de avaliação de sustentabilidade integrado e globa para ecossistemas florestais: Bioenergia, produtos derivados de madeira e coprodutos, Departamento de Ciências da Vida da Faculdade de Ciências e Tecnologia, Universidade de Coimbra, 2015.

[21] J. Jensen, J. Morinelly, A. Aglan, A. Mix, D.R. Shonnard, Kinetic characterization of biomass dilute sulfuric acid hydrolysis: mixtures of hardwoods, softwood, and switchgrass, AIChE J. 54 (2008) 1637-1645.

[22] M.H. Thomsen, H. Haugaard-Nielsen, Sustainable bioethanol production combining biorefinery principles using combined raw materials from wheat undersown with clover-grass, J. Ind. Microbiol. Biotechnol. 35 (2008) $303-311$.

[23] C. Martín, M.H. Thomsen, H. Hauggaard-Nielsen, A. BelindaThomsen, We oxidation pretreatment, enzymatic hydrolysis and simultaneous saccharification and fermentation of clover-ryegrass mixtures, Bioresour. Technol. 99 (2008) 8777-8782.

[24] R. Yánez, B. Gómez, M. Martínez, B. Gullón, J.L. Alonso, Valorization of an invasive woody species, Acacia dealbata, by means of Ionic liquid pretreatment and enzymatic hydrolysis, J. Chem. Technol. Biotechnol. 89 (2014) 1337-1343.

[25] M. Dusselier, P. Van Wouwe, A. Dewaele, E. Makshina, B.F. Sels, Lactic acid as a platform chemical in the biobased economy: the role of chemocatalysis,
Energy Environ. Sci. 6 (2013), 1415-1415.

[26] A. Romaní, H.A. Ruiz, F.B. Pereira, L. Domingues, J.A. Teixeira, Effect of hemicellulose liquid phase on the enzymatic hydrolysis of autohydrolyzed Eucalyptus globulus wood, Biomass Convers. Biorefinery 4 (2014) 77-86.

[27] J. Dibdiakova, L. Wang, H. Li, Characterization of ashes from Pinus sylvestris forest biomass, Energy Procedia 75 (2015) 186-191.

[28] P. Moniz, L. João, L.C. Duarte, L.B. Roseiro, C.G. Boeriu, H. Pereira, F. Carvalheiro, Fractionation of Hemicelluloses and Lignin from Rice Straw by Combining Autohydrolysis and Optimised Mild Organosolv Delignification, 2015.

[29] L.P. Ramos, The chemistry involved in the steam treatment of lignocellulosic materials, Quím. Nova 26 (2003) 863-871.

[30] H.A. Ruiz, M.H. Thomsen, H.L. Trajano, Hydrothermal Processing in Biorefineries: Production of Bioethanol and High Added-value Compounds of Second and Third Generation Biomass, Springer International Publishing, 2017.

[31] M.L. Soto, A. Moure, H. Domínguez, J.C. Parajó, Recovery, concentration and purification of phenolic compounds by adsorption: a review, J. Food Eng. 105 (2011) $1-27$

[32] C.E. Costa, A. Romaní, J.T. Cunha, B. Johansson, L. Domingues, Integrated approach for selecting efficient Saccharomyces cerevisiae for industrial lignocellulosic fermentations: importance of yeast chassis linked to process conditions, Bioresour. Technol. 227 (2017) 24-34.

[33] K. Ma, G. Hu, L. Pan, Z. Wang Y. Zhou, Y. Wang Z. Ruan, M. He, Highly efficient production of optically pure l-lactic acid from corn stover hydrolysate by thermophilic Bacillus coagulans, Bioresour. Technol. 219 (2016) 114-122.

[34] P. Gullón, B. Gullón, A. Cardelle-Cobas, J.L. Alonso, M. Pintado, A.M. Gomes, Effects of hemicellulose-derived saccharides on behavior of Lactobacilli under simulated gastrointestinal conditions, Food Res. Int. 64 (2014) 880-888.

[35] M.R. Siqueira, V. Reginatto, Inhibition of fermentative H2 production by hydrolysis byproducts of lignocellulosic substrates, Renew. Energy 80 (2015) 109-116.

[36] Y. Pu, T. Treasure, R. Gonzalez, R.A. Venditti, H. Jameel, Autohydrolysis pretreatment of mixed softwood to produce value prior to combustion, BioEnergy Res. 6 (2013) 1094-1103.

[37] K.L. Chin, P.S. H'ng, M.T. Paridah, K. Szymona, M. Maminski, S.H. Lee, W.C. Lum, M.Y. Nurliyana, M.J. Chow, W.Z. Go, Reducing ash related operation problems of fast growing timber species and oil palm biomass for combustion applications using leaching techniques, Energy 90 (2015) 622-630.

[38] D. Kim, K. Lee, K.Y. Park, Upgrading the characteristics of biochar from cellulose, lignin, and xylan for solid biofuel production from biomass by hydrothermal carbonization, J. Ind. Eng. Chem. 42 (2016) 95-100.

[39] A. Demirbaș, Mechanisms of liquefaction and pyrolysis reactions of biomass, Energy Convers. Manag. 41 (2000) 633-646.

[40] F. López, A. Pérez, M.A.M. Zamudio, H.E. De Alva, J.C. García, Paulownia as raw material for solid biofuel and cellulose pulp, Biomass Bioenergy 45 (2012) 77-86.

[41] M.T. Holtzapple, H.S. Caram, A.E. Humphrey, A comparison of two empirical models for the enzymatic hydrolysis of pretreated poplar wood, Biotechnol. Bioeng. 26 (1984) 936-941.

[42] A. Romaní, G. Garrote, J.L. Alonso, J.C. Parajó, Experimental assessment on the enzymatic hydrolysis of hydrothermally pretreated Eucalyptus globulus wood, Ind. Eng. Chem. Res. 49 (2010) 4653-4663.

[43] A. Singh, P. Sharma, A.K. Saran, N. Singh, N.R. Bishnoi, Comparative study on ethanol production from pretreated sugarcane bagasse using immobilized Saccharomyces cerevisiae on various matrices, Renew. Energy 50 (2013) 488-493.

[44] M. Michelin, J.A. Teixeira, Liquid hot water pretreatment of multi feedstocks and enzymatic hydrolysis of solids obtained thereof, Bioresour. Technol. 216 (2016) 862-869. 